\title{
New Release of Evidence-Based Clinical Practice Guideline: Comprehensive Pediatric Eye and Vision Examination
}

\author{
Tamara V Petrosyan \\ SUNY College of Optometry, New York, USA \\ *Corresponding author: Tamara V Petrosyan, Associate Clinical Professor, SUNY College of Optometry, \\ New York, USA, Tel: +1 6317932386; E-mail: tvpetrosyan@gmail.com
}

Received Date: 11 October, 2017; Accepted Date: 18 October, 2017; Published Date: 26 October, 2017

In the United States, an estimated $20 \%$ of preschoolers have a vision problem [1] and $25 \%$ of school-age children wear some form of vision correcting lenses [2]. An ocular or vision disorder in childhood can manifest and negatively impact a person throughout his or her entire life. Eye and vision disorders have been linked to abnormal development [3], poor school performance [4] and level of education [5], as well as affecting employment and social interactions [6,7]. The American Optometric Association (AOA) recognizes the importance of early diagnosis and intervention of eye and vision disorders and has released a new evidence-based Clinical Practice Guideline (CPG) for the comprehensive pediatric eye and vision examination. CPGs contain recommendations "intended to optimize patient care that are informed by a systematic review of the evidence and an assessment of the benefits and harms of alternative care options [8]." The new guidelines describe procedures to evaluate the ocular and visual health of infants and children and recommends timely diagnosis, treatment, and inter professional care of the pediatric patient. The "clinical recommendations in this guideline are evidence-based statements regarding patient care that are supported by the scientific literature or consensus of professional opinion when no quality evidence was discovered [9]."

In 2012, the total cost of vision loss and eye disorders in children less than 18 years was an estimated $\$ 5.9$ billion [10]. The most common cause of correctable reduced vision in children is refractive error $[11,12]$, up to the age of 6 , the visual system is sensitive to visual conditions which may blur vision or interfere with binocularity. This interference, if left without intervention, may lead to amblyopia, the leading cause of monocular vision loss in children. While amblyopia may be treated in both adults and children, early diagnosis and treatment yields a more favorable outcome [13]. The second most prevalent vision conditions in children are accommodative and binocular in nature. $8.3 \%$ of school-age [14] and 13\% of fifth and sixth grade children [15] are affected by convergence insufficiency and $5 \%$ of school age children have accommodative disorders [16]. Pediatric ocular disease and systemic disease which may affect the ocular and visual system, while rare, can be vision threatening and timely diagnosis and treatment is key.

Clinical experience and research have shown that at 6 months, the average child has reached a number of critical developmental milestones, making this an appropriate age for the first comprehensive eye and vision examination. The AOA recommends that children be seen at 6 months, at least once between the ages of 3 and 5 , at the beginning of primary school, and then annually or as recommended by their doctor [9]. Each state has individual requirement relating to vision evaluation for children attending school. These requirements range from no guidelines, to requiring a vision screening, to requiring a comprehensive evaluation [17]. Less than $22 \%$ of preschoolers receive some type of vision screening and less than $15 \%$ receive an examination by an eye care professional [18]. The access to pediatric comprehensive eye and vision examinations has increased in the past decade with the development of such resources as the Infant SEE program and the Affordable Care Act (ACA). The InfantSEE program provides a one time, no cost comprehensive evaluation to infants 6-12 months of age, irrespective of their insurance status. Participating providers can be found through the find-a-doc application on www.infantsee.org. The ACA has listed pediatric comprehensive eye and vision examinations by a doctor of optometry or ophthalmologist as one of the ten essential health benefits, making them a covered service through insurance programs [19]. 
Citation: Petrosyan TV (2017) New Release of Evidence-Based Clinical Practice Guideline: Comprehensive Pediatric Eye and Vision Examination. Curr Adv Ophthalmol 2017: 5-6. DOI: https://doi.org/10.29199/2638-9940/CAOP-101014.

Disorders such as significant refractive error, amblyopia, strabismus, and other binocular vision disorders can have significant long-term consequences for a child if undetected and untreated. The cost of treating a longstanding eye and vision disorder may be significantly higher than the cost of early diagnosis and treatment. Because the visual system develops rapidly and is sensitive to interference, a comprehensive eye and vision examination in infants and children by a doctor of optometry or ophthalmologist is imperative for timely diagnosis and treatment of these potential problems. The full guidelines to the new evidence-based clinical practice guideline for the comprehensive pediatric eye and vision examination can be freely accessed at: http://aoa.uberflip. com/i/807465-cpg-pediatric-eye-and-vision-examination

\section{References}

1. Giordano L, Friedman DS, Repka MX, Ibironke J, Hawes P, et al (2009) Prevalence of refractive error among preschool children in an urban population: the Baltimore Pediatric Eye Disease Study. Ophthalmology 116: 739-746.

2. Kemper AR, Bruckman D, Freed GL (2004) Prevalence and distribution of corrective lenses among school-age children. Optom Vis Sci 81: 7-10.

3. Roch-Levecq AC, Brody BL, Thomas RG, Brown SI (2008) Ametropia, preschoolers' cognitive abilities, and effects of spectacle correction. Arch Ophthalmol 126: 252-258.

4. Maples WC (2003) Visual factors that significantly impact academic performance. Optometry 74: 35-49.

5. Goldstand S, Koslowe KC, Parush S (2005) Vision, visual-information processing, and academic performance among seventh-grade schoolchildren: a more significant relationship than we thought? Am J Occup Ther 59: 377-389.

6. Mojon-Azzi SM, Kunz A, Mojon DS (2011) Strabismus and discrimination in children: are children with strabismus invited to fewer birthday parties? Br J Ophthalmol 95: 473-476.

7. Davidson S, Quinn GE (2011) The impact of pediatric vision disorders in adulthood. Pediatrics 127: 334-339.
8. Institute of Medicine (US) Committee on Standards for Developing Trustworthy Clinical Practice Guidelines, Graham R, Mancher M, Wolman DM, Greenfield S, et al. (2011) Clinical Practice Guidelines We Can Trust. The National Academies Press US Washington (DC).

9. AOA Evidence-Based Optometry Guideline Development Group (2017) Evidence-Based Clinical Practice Guideline: Comprehensive Pediatric Eye and Vision Examination. AOA Optometric Clinical Practice Guidelines. American Optometric Association, St. Louis, USA.

10. Wittenborn JS, Zhang X, Feagan CW, Crouse WL, Shrestha S, et al. (2013) The economic burden of vision loss and eye disorders among the United States population younger than 40 years. Ophthalmology 120: $1728-1735$.

11. Tarczy-Hornoch K, Cotter SA, Borchert M, McKean-Cowdin R, Lin $\mathrm{J}$, et al. (2013) Prevalence and causes of visual impairment in Asian and non-Hispanic white preschool children: Multi-Ethnic Pediatric Eye Disease Study. Ophthalmology 120: 1220-1226

12. Multi-Ethnic Pediatric Eye Disease Study Group (2009) Prevalence and causes of visual impairment in African-American and Hispanic preschool children: the Multi-Ethnic Pediatric Eye Disease Study. Ophthalmology 116: 1990-2000.

13. Scheiman MM, Hertle RW, Beck RW, Edwards AR, Birch E, et al. (2005) Randomized trial of treatment of amblyopia in children aged 7 to 17 years. Arch Ophthalmol 123: 437-447.

14. Cooper J, Jamal N (2012) Convergence insufficiency-a major review. Optometry 83: 137-158.

15. Rouse MW, Borsting E, Hyman L, Hussein M, Cotter SA, et al. (1999) Frequency of convergence insufficiency among fifth and sixth graders. The Convergence Insufficiency and Reading Study (CIRS) group. Optom Vis Sci 76: 643-649.

16. Scheiman M, Gallaway M, Coulter R, Reinstein F, Ciner E, et al. (1996) Prevalence of vision and ocular disease conditions in a clinical pediatric population. J Am Optom Assoc 67: 193-202.

17. American Association for Pediatric Ophthalmology and Strabismus. State-by-state vision screening requirements.

18. Centers for Disease Control and Prevention, Vision Health Initiative. Centers for Disease Control and Prevention, Atlanta, USA.

19. Obamacare Facts, Vision Insurance. 